\title{
Brasil em Jogo: Futebol, arte e política em campo
}

\section{Brasil em Jogo: Football, art and politics on the field}

Paloma Bianchi ${ }^{1}$

Milene Lopes Duenha ${ }^{2}$

Cassiana dos Reis Lopes ${ }^{3}$

Everton Lampe de Araújo ${ }^{4}$ 


\section{Resumo}

Um país partido, e duas grandes torcidas sofrem as consequências de jogadas desastrosas. Esse é o cenário político brasileiro em que se desenvolve Brasil em Jogo (2016), um trabalho do coletivo Mapas e Hipertextos, que se apropria da estrutura do jogo de futebol para questionar modos de fazer/pensar arte e política. Neste artigo se discutem alguns aspectos do processo de criação de Brasil em Jogo tratando de seus impulsos - vinculados aos acontecimentos na política representativa brasileira -, seus meios de desenvolvimento - explorando características do teatro e da performance - e suas reverberações no ato relacional na cidade de Florianópolis-SC.

Palavras-chave: Futebol; política; Brasil; espetáculo; representação.

\section{Abstract}

A broken country, two big crowds undergo the consequences of devastating moves. This is the Brazilian political scenario in which Brasil em Jogo (2016), a work of Mapas e Hipertextos collective, is established. It appropriates the football match structure to question the art and politics ways of doing/thinking. This article discusses some aspects of Brasil em Jogo's creation process, addressing what triggered it- its bounds to events in Brazilian representative politics -, its development means - exploring theater and performance characteristics - and its reverberations in the relational act in the city of Florianópolis - SC.

Keywords: Football; politics; Brazil; spectacle; representation.

ISSN: 1414.5731

E-ISSN: 2358.6958

\footnotetext{
1 Doutoranda do Programa de Pós-Graduação em Teatro (PPGT). Universidade do Estado de Santa Catarina (UDESC/CEART) bianchi.paloma@gmail.com

2 Doutoranda do Programa de Pós-Graduação em Teatro (PPGT). Universidade do Estado de Santa Catarina (UDESC/CEART) miduenha@yahoo.com.br

${ }^{3}$ Doutoranda do Programa de Pós-Graduação em Teatro (PPGT). Universidade do Estado de Santa Catarina (UDESC/CEART) cassiana.reis.lopes@gmail.com

${ }^{4}$ Doutorando do Programa de Pós-Graduação em Teatro (PPGT). Universidade do Estado de Santa Catarina (UDESC/CEART) evertonlampe@gmail.com
} 


\section{Seleção dos times e primeiras táticas de jogo}

Abril, 2016, Florianópolis, Santa Catarina, Brasil. No governo federal, a presidente Dilma Rousseff5; na vice-presidência, Michel Temer ${ }^{6}$. Na presidência da Câmara dos Deputados, Eduardo Cunha7. Na presidência do Senado, Renan Calheiros ${ }^{8}$.

O coletivo de pesquisa e criação Mapas e Hipertextos ${ }^{9}$ se reunia regularmente todas as terças e sextas-feiras de 2016 em uma das salas do prédio de Artes Cênicas no Centro de Artes (CEART) da Universidade do Estado de Santa Catarina (UDESC). Na terça-feira, 19 de abril de 2016, desenvolvíamos um procedimento que envolvia o falar e o mover concomitantemente: o gesto que obedece ao que é falado, a fala que obedece ao que é gesticulado. Enquanto isso, na arena central do CEART, dezenas de discentes das graduações e das pós-graduações e alguns docentes se reuniam em assembleia contra o impedimento (golpe) iminente da presidente Dilma Rousseff. As vozes diziam em coro: "Fora Cunha"; "Não vai ter golpe, vai ter luta"; "Vem, vem, vem pra rua, vem contra o golpismo"; "Nas ruas, nas praças, quem disse que não viu? Aqui está presente o movimento estudantil"; "No meu país eu boto fé, porque ele é governado por mulher".

Uma única parede nos separava dos gritos de resistência. O que era cantado e gritado fora da sala acabou por emoldurar e determinar os gestos que fazíamos em ensaio, não havia como ignorar aquela força que se configurava na arena. Mas apenas corresponder aos gritos de resistência com nossos gestos não pareceu suficiente. $O$ sentimento de angústia e revolta que estávamos vivenciando naqueles dias de iminente golpe (parlamentar/midiático/judiciário) nos obrigou a parar o que fazíamos e discutir como nos posicionaríamos diante desse contexto - não individualmente, mas como coletivo de arte. O pesquisador e crítico de arte francês Paul Ardenne (2006) coloca que a arte contextual é aquela que se fundamenta a partir de uma situação diretamente conectada ao que se vive no aqui-agora; um modo de "[...] co-presença, em virtude de uma lógica de implicação que vê a obra de arte diretamente conectada a um sujeito que pertence à história imediata" ${ }^{10}$ (Ardenne, 2006, p. 13). Para ele, o artista pode ser compreendido como aquele que tece com o mundo, da mesma maneira que os contextos tecem, envolvem e determinam o vivido. $O$ artista da arte contextual trata de:

[...] falar igual (como todo cidadão ao que concerne a vida pública em um meio

\footnotetext{
${ }^{5}$ Dilma Rousseff, presidente pelo PT reeleita em 2014. Rousseff, na época da ditadura, participou da luta armada de esquerda contra o governo (golpe) civil-militar.

${ }^{6}$ Devido à coligação entre PT e PMDB, Michel Temer (PMDB) foi vice de Dilma Rousseff em ambos os mandatos da presidente.

${ }^{7}$ Deputado federal pelo PMDB do Rio Janeiro, Cunha é evangélico da Assembleia de Deus.

${ }^{8}$ Senador por Alagoas pelo PMDB.

${ }^{9}$ Trata-se de um coletivo de criação em artes presenciais, com sede em Florianópolis-SC, que opera na intersecção entre dança, performance e teatro desde o ano de 2012, buscando formas de convívio e criação menos hierárquicas. As integrantes atuais são: Cassiana dos Reis Lopes (atriz, performer, cientista social, fotógrafa e mestranda em teatro), Diana Gilardenghi (dançarina, performer e professora de dança contemporânea), Diana Piazza (dançarina, performer, recreadora e salva-vidas), Everton Lampe (performer, ator e encenador teatral, mestrando em teatro), Giorgio Gislon (ator, mestre em literatura e estudos latino-americanos e professor), Inês Saber (dançarina, performer, professora de inglês e português, mestranda em teatro), Luana Leite (atriz, dançarina, performer e mestranda em teatro), Milene Duenha (dançarina, atriz, performer, professora e doutoranda em teatro), Paloma Bianchi, (dançarina, performer, professora e doutoranda em teatro), Raquel Purper (dançarina, atriz, performer, diretora, professora e doutoranda em teatro) e Thaina Gasparoto (atriz, dançarina e performer). Mais informações sobre o coletivo podem ser consultadas no site do grupo: <https://mapasehipertextos.wordpress.com/>.

10 "[...] co-presencia, en virtud esta vez de una lógica de implicación que ve la obra de arte directamente conectada a un sujeto que pertenece a la historia inmediata". (Tradução nossa).
}

Paloma Bianchi

Milene Lopes Duenha 
democrático) e de outra maneira (utilizando meios de ordem artística capazes de suscitar uma atenção mais aguda, mais singular que a que permite a linguagem social). Se trata de fazer da linguagem da arte uma linguagem por sua vez integrada, capaz de ser ouvida, e dissonante, ou seja, cujo propósito vem a por em debate a opinião dominante (Ardenne, 2006, p. 26) ${ }^{11}$.

Essa é uma discussão pertinente ao coletivo Mapas e Hipertextos, posto que suas proposições artísticas são efeito de um processo de percepção dos contextos sociais, políticos, econômicos e culturais do cotidiano, enfatizando suas contradições e idiossincrasias, buscando também formas menos hierárquicas de convívio em contraposição a um regime meritocrático e de forças opressoras. Dessa maneira, e no contexto específico em que vivíamos, seria incoerente tanto não aceitarmos aquele atravessamento, quanto não agirmos a partir daquilo que estávamos sentindo diante da iminência de um golpe e de todas as consequências políticas e sociais dele. Nossa intenção era discutir uma possível ação artística que, além de criar resistência àquilo que estava em andamento na política por uma perspectiva ativista, também evidenciasse o lugar da criação artística contextual. Depois do compartilhamento de pontos de vista e exposição de nossas angústias, um dos integrantes do coletivo, Everton Lampe, sugeriu desenvolvermos uma ação usando as estratégias de um jogo de futebol. Tal escolha nos pareceu pertinente, uma vez que a exploração da estrutura futebolística e suas inúmeras camadas de sentido nos abriam múltiplas possibilidades de criação.

Em relação à possível recepção do público, acreditávamos que poderíamos nos pautar no fato de a linguagem do futebol ser de fácil assimilação, dado que a grande maioria dos brasileiros entende suas regras e se atrai pelo jogo. Aludiríamos também ao fato de o Brasil ter o estereótipo de ser "o país do futebol". No que diz respeito às questões políticas, também nos parecia óbvio que há um jogo que é jogado pelos ditos "representantes do povo", com seus conchavos, seus acordos e suas guerras pelo poder. A proposta de criar dois times também nos pareceu adequada, uma vez que, aparentemente, no processo de impedimento (golpe), a estratégia política/midiática usada foi reforçar as diferenças e a separação entre cada time por meio do esforço em rebaixar a imagem do time opositor e enaltecer a imagem do seu time do coração. Assim, configuramos dois times, que retratariam dois modos de pensar/agir supostamente opostos.

Além dessa situação atual, há historicamente uma relação estreita entre contexto social e futebol. Em diversos países da América Latina, como ocorreu na Copa de 1978 na Argentina ${ }^{12}$, o futebol foi usado como propaganda de governos antidemocráticos (Damo, 2001). Já no Brasil, este fato tornou-se presente na emblemática Copa de $1970^{13}$ durante o governo do presidente (ditador) Emílio Garrastazu Médici.

\footnotetext{
11 "[...] hablar igual (como todo ciudadano al que concierne la vida pública en un medio democrático) y de otra manera (utilizando medios de orden artístico capaces de suscitar una atención más aguda, mas singular que la que permite el lenguaje social). Se trata de hacer del lenguaje del arte un lenguaje a la vez integrado, por lo tanto capaz de ser oído, y disonante, es decir, cuyo propósito viene a poner en debate la opinión dominante".(Tradução nossa).

${ }^{12}$ Para mais informações, acessar:

$<$ http://observatoriodasmetropoles.net/index.php?option=com_k2\&view=item\&id=362\%3Acopa-em-discussão- $n^{0}-12$-argentina-1978-futebol-e-ditadura\&ltemid=164\&lang=pt>. Acesso em: 22 abr. 2017.

${ }^{13} \mathrm{~A}$ emblemática Copa de 1970 no Brasil serviu à ditadura como promoção do governo cruel do presidente Emílio Garrastazu Médici, grande admirador de futebol. Médici não só opinava na escalação da seleção brasileira como ele mesmo ergueu a taça da vitória da final do campeonato mundial, quando esta aportou no País (Lee-Meddi, 2010).
} 
De acordo com o jornalista Carlos Ferreira Vilarinho (2010), o presidente (ditador), conhecido pelo seu amor ao esporte, ditava os percursos da seleção, tendo inclusive demitido João Saldanha, técnico da seleção brasileira, por este ser um notório militante comunista ${ }^{14}$.

Percebemos também que o golpe de estado que o Brasil vivenciava em abril de 2016 continha muita semelhança com o golpe de estado vivenciado (também no mês de abril) em 1964: o apoio da mídia de massa e das grandes empresas que faziam o Estado sujeito a seus interesses ${ }^{15}$; o uso de estratégias de distração da população lançando polêmicas que dividiriam a população em dois polos; a exposição de ideias conservadoras $^{16}$. As discussões entre esses grupos polarizados se intensificavam e se assemelhavam às brigas futebolísticas que consistiam na defesa de seus respectivos times por meio de agressões físicas e verbais, também reiterando os binarismos entre rico/pobre, centro/periferia, negro/branco. O pesquisador brasileiro Arlei Sander Damo (2001) aponta que a noção de pertencimento que o futebol carrega traz características políticas. Parafraseando o poeta brasileiro Carlos Drummond de Andrade, Damo sugere que a escolha do time se assemelha sobremaneira à necessidade política de escolha de ser liberal, socialista ou reacionário: a rivalidade entre torcedores se equipara à rivalidade política. Em 2016, além de ditar comportamento e evidenciar a polarização, o futebol foi evocado contraditoriamente nas manifestações de pautas conservadoras e de interesses privados, cujo "uniforme" eram as camisas amarelas da Confederação Brasileira de Futebol (CBF), investigada pelo Comitê de Ética da Federação Internacional de Futebol (FIFA), ambas instituições envolvidas em problemas relacionados à corrupção ${ }^{17}$. Mas nada disso vinha ao caso para o grupo de amarelo que gritava "contra a corrupção". O importante era mostrar o patriotismo e levantar a bandeira nacional com o mesmo fervor com que foi levantada durante a Copa do Mundo, para fazer com que o Brasil tomasse "o rumo certo".

Diante do fato de que não se tratava unicamente de um processo de impedimento (golpe), mas de como diferentes poderes se articulam nas decisões da vida política, envolvendo desde movimentos sociais amplamente conhecidos até interesses pessoais e sobreposições ideológicas, tomar "partido" e alimentar nossos procedimentos artísticos desse contexto nos pareceram a alternativa mais plausível diante do caos gerado pela política partidária nacional. Mesmo enxergando as diferenças e contradições internas de cada grupo, uma coisa nos parecia certa: tratava-se do embate entre dois times. De um lado os camisas verde e amarela; de outro, os camisas vermelhas. Dois grupos muito distintos, armados de bandeiras, camisas, pautas, e

\footnotetext{
${ }^{14}$ A mídia da época divulgou que o motivo da demissão de João Saldanha teria sido a sua recusa ao pedido de Médici em escalar o jogador Dadá Maravilha (ver: <http://acervo.oglobo.globo.com/fatos-historicos/joao-saldanha-sai-apos-peitar-medici-nao-convocar-dario-para-copa-de-70-11811737>. Acesso em: 22 abr. 2017. Mas em seu livro Quem derrubou João Saldanha (2010), Vilarinho rebate tal razão, afirmando que Médici demitiu Saldanha por ele ser membro do Partido Comunista.

${ }^{15}$ Mais informações podem ser conferidas em:

<http://www.cartamaior.com.br/?/Editoria/Politica/A-grande-midia-e-o-golpe-de-64/4/14698 >,

$<$ https://www.cartacapital.com.br/politica/perguntas-e-respostas-do-financiamento-de-campanha-eleitoral-1319.html > e < http://voyager1.net/politica/midia-informacao-e-politica/>. Acesso em: 25 abr. 2017.

${ }^{16}$ A exemplo da Marcha da Família com Deus pela Liberdade. Diversas manifestações a favor da estrutura tradicional de família e contra uma suposta ameaça comunista que ocorrerem entre março e junho de 1964 durante o então presidente João Goulart.

${ }^{17}$ Para mais informações, acesse:

<https://www.cartacapital.com.br/sociedade/entenda-o-escandalo-da-fifa-e-da-cbf-4139.html>. Acesso em: 10 abr. 2017.
}

Paloma Bianchi

Milene Lopes Duenha 
patos $^{18}$, defendiam suas ideias tão intensamente quanto se faz nos jogos em estádios de futebol.

A atenção aos acontecimentos daquele período e a urgência em tomar posição em relação ao que vivíamos foram o nosso motor para a construção da ação Brasil em Jogo e isso fez com que algumas consequências fossem geradas. Identificar a linguagem investigada como performance, teatro ou dança não sobressaiu à necessidade de articular um modo artístico ${ }^{19}$ de vivenciar os acontecimentos políticos no País. Brasil em Jogo revelou-se para o grupo a partir das investidas na estrutura e nas regras do futebol. As leituras diversas dos fatos políticos realizadas pelas artistas do Mapas e Hipertextos se articulavam em jogadas que, a princípio, poderiam ser associadas a uma estrutura dramatúrgica convencionalmente pertencente ao teatro, mas essa mesma estrutura também se modificava a partir da sequência de acontecimentos políticos do País nesse período de realização da ação. A impermanência do roteiro/dramaturgia dependia dos (e jogava com os) acontecimentos reais. Muitas vezes, a realidade dos acontecimentos políticos e a estrutura do futebol não convergiam, pois enquanto as regras do jogo de futebol são claras e relativamente estáveis, as regras do jogo político são obscuras e alteradas de acordo com os interesses de alguns jogadores - "craques", o que também se evidenciou no trabalho.

\section{Treinamento}

Iniciamos o processo de criação convocando os representantes políticos/jogadores e elencando os acontecimentos do jogo. Ao longo de todo o processo, discutimos sobre como tomaríamos partido, uma vez que muitos de nós questionavam tanto as ações do governo Dilma quanto as propostas da oposição. Optamos por evidenciar não somente as estratégias não idôneas da então oposição ao governo de Dilma, como também as incongruências do governo da presidenta. Em discussões, escalamos os possíveis representantes políticos/jogadores de cada time. Decidimos criar máscaras com as fotos dos representantes políticos/jogadores e fazer camisetas de cores diferentes para cada um dos times, com seus nomes identificados. No time de Dilma, depois nomeado de time de Lula, por este ser definido como o verdadeiro capitão do time, estavam presentes Lula ${ }^{20}$, Dilma, Jean Wyllys ${ }^{21}$, Katia Abreu², Tiririca ${ }^{23}$, Chico Buarque ${ }^{24}$, Jandira Feghali25 e Michel Temer. No time adversário, nomeado de time de Cunha, constavam o próprio Cunha como capitão, Bolsonaro ${ }^{26}$,

\footnotetext{
${ }^{18} \mathrm{O}$ grupo que vestia as camisas amarelas teve incentivo da FIESP (Federação das Indústrias do Estado de São Paulo). Em algumas das manifestações contra o aumento de impostos um pato de borracha gigante começou a figurar nas manifestações, junto com a inscrição "Não vou pagar o pato", o que se multiplicou e se transformou em símbolo das manifestações da direita. Porém o projeto do pato utilizado nas manifestações, e patrocinado pela FIESP, havia sido desenvolvido pelo artista plástico holandês Florentijn Hofman, que acusou a FIESP de ter feito plágio de sua obra Rubber Duck, exposta em São Paulo em 2008. A mesma empresa que fabricou o pato de Hofman foi contratada pela FIESP para fabricar o seu. Mais informações podem ser encontradas em: $<$ <ttp://www.bbc.com/portuguese/noticias/2016/03/160329_pato_fiesp_fs>. Acesso em: 24 abr. 2017.

${ }^{19} \mathrm{O}$ que não impediu de nos apropriarmos dessas linguagens para fazer uma leitura da ação Brasil em Jogo para este artigo.

${ }^{20}$ Luís Inácio Lula da Silva foi presidente do Brasil pelo PT por dois mandatos consecutivos.

${ }^{21}$ Deputado federal pelo PSOL do Rio de Janeiro.

${ }^{22}$ Foi ministra da Agricultura durante o segundo governo de Dilma, representando a bancada ruralista. É senadora pelo PMDB de Tocantins.

${ }^{23}$ Cantor, compositor e humorista, é deputado federal pelo PR de São Paulo.

${ }^{24}$ Cantor, compositor e escritor carioca, se auto exilou na época da ditadura. Conhecido por apoiar os governos de Lula e Dilma, do PT.

${ }^{25}$ Deputada federal pelo PCdoB do Rio de Janeiro.

${ }^{26}$ O militar Jair Bolsonaro cumpre o sexto mandato como deputado federal pelo Partido Social Cristão (PSC) do Rio de Janeiro.
} 
Feliciano ${ }^{27}$, William Bonner ${ }^{28}$, César Souza $^{29}$, Amin $^{30}$, Serra $^{31}$, Aécio ${ }^{32}$ e Alckmin ${ }^{33} . \mathrm{Na}$ arbitragem, o juiz Moro ${ }^{34}$, e na narração, Galvão Bueno ${ }^{35}$. Em nosso jogo, a posição do trabalhadora/trabalhador foi ocupada por uma bola murcha e suja, na qual escrevemos a palavra "trabalhador".

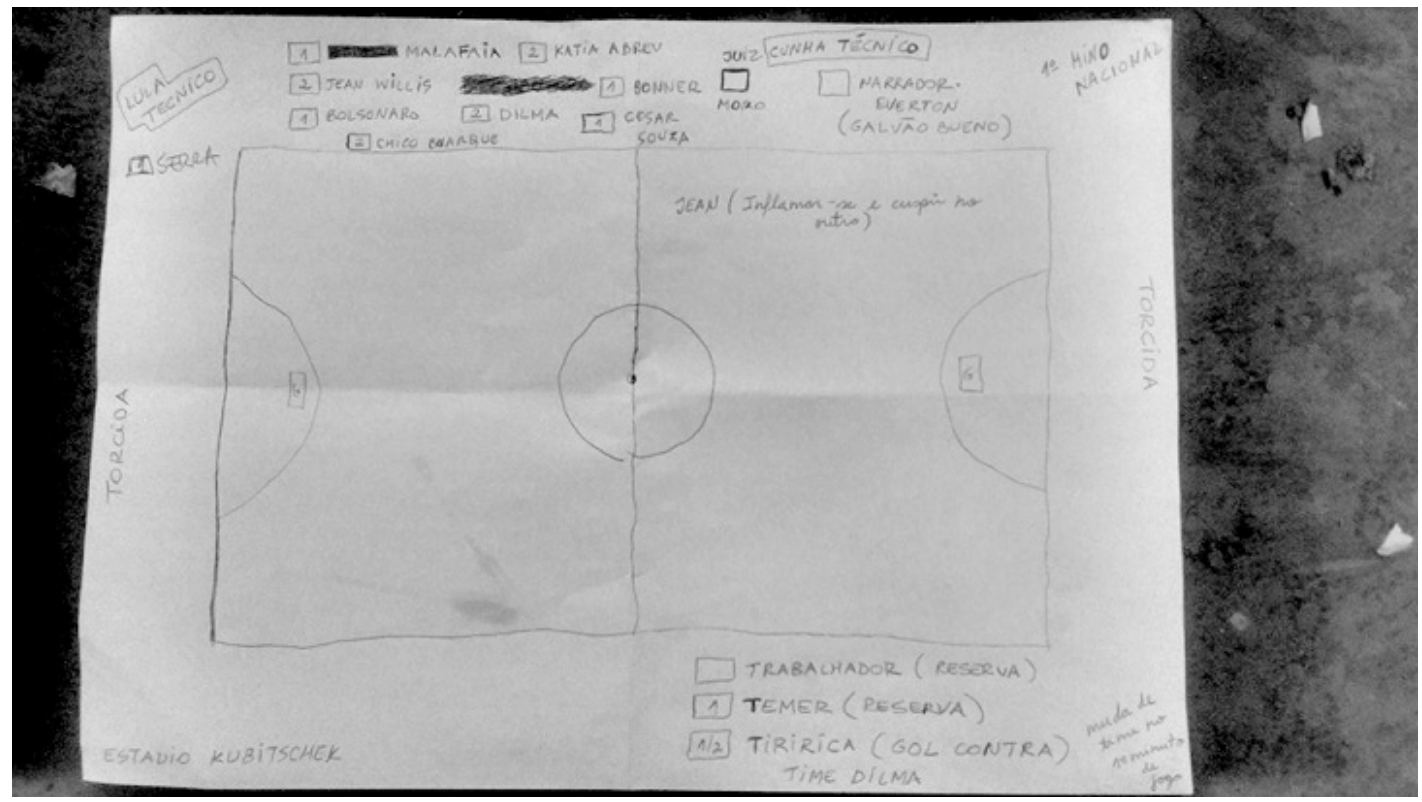

Imagem de esquema da ação Brasil em Jogo. Foto: Acervo do grupo.

Dentre os possíveis acontecimentos, delimitamos algumas ações que contemplassem tanto as regras do futebol quanto o jogo político que se apresentava. Assim, os primeiros acontecimentos elencados foram: gol contra de Kátia Abreu em alusão à postura dúbia da ministra ${ }^{36 ;}$ barreira de defesa do time de Lula posta do lado oposto da quadra, favorecendo o time adversário37; briga entre Dilma e Cunha durante uma pedalada de Dilma, aludindo às pedaladas fiscais, mote do processo de impedimento; tentativa de Dilma de colocar Lula de volta ao time, sem sucesso 38 ; ação de Kátia Abreu de jogar vinho no rosto de Serra39; pedido de Tiririca para trocar de time em menção a sua mudança de posicionamento em relação a seu voto favorável ao impedimento (golpe) da presidenta; cuspida de Jean Wyllys em Bolsonaro em resposta aos

\footnotetext{
${ }^{27}$ Marco Antônio Feliciano, deputado federal pelo PSC de São Paulo, é pastor da Assembleia de Deus. Em 2013, foi presidente da Comissão de Direitos Humanos e Minorias (CDHM) da Câmara dos Deputados.

${ }_{28}^{2}$ Jornalista da Rede Globo, é editor chefe e apresentador do Jornal Nacional.

${ }^{29}$ Deputado federal pelo PSD de Santa Catarina.

${ }^{30}$ Esperidião Amin está na política desde o governo militar. Atualmente é deputado federal pelo PP de Santa Catarina.

${ }^{31}$ Senador pelo PSDB de São Paulo, ocupou o cargo de ministro de Relações Exteriores do governo golpista de Michel Temer.

${ }^{32}$ Aécio Neves é presidente do PSDB e senador por Minas Gerais pelo mesmo partido. Concorreu ao cargo de presidente, tendo perdido as eleições para Dilma Rousseff.

${ }^{33}$ É governador do Estado de São Paulo pelo PSDB, cargo que ocupa pela quarta vez. É católico da organização Opus Dei.

${ }^{34} \mathrm{O}$ juiz Sergio Moro comanda os julgamentos da Operação Lava Jato desde 2014.

${ }^{35}$ Locutor de esportes da Rede Globo de Televisão.

${ }^{36}$ Parece-nos incoerente um governo dito de esquerda como o de Dilma Rousseff ter como ministra da Agricultura, Pecuária e Abastecimento uma das líderes do Agronegócio. A presidenta Dilma, durante seu mandato, congelou o processo de reforma agrária. Para mais informações ver: <http://www1.folha.uol.com.br/ poder/2016/03/1754395-governo-dilma-congela-reforma-agraria.shtml>. Acesso em: 22 abr. 2017.

${ }^{37}$ Com esta ação quisemos oferecer uma situação dúbia aludindo às diversas situações em que os governos do PT optaram por se aproximar dos grandes empresários em detrimento da grande massa de trabalhadoras/trabalhadores.

${ }^{38}$ A exemplo da tentativa de nomeação do ex-presidente para Ministro da Casa Civil.

${ }^{39} \mathrm{Em}$ jantar em Brasília, Katia Abreu jogou uma taça de vinho no rosto de José Serra em razão de um seu comentário machista. Para mais informações, acesse: <http://www.pragmatismopolitico.com.br/2015/12/katia-abreu-explica-por-que-jogou-vinho-na-cara-de-jose-serra.html>. Acesso em: 22 abr. 2017.
}

Paloma Bianchi

Milene Lopes Duenha 
seus xingamentos e posturas homofóbicas ${ }^{40}$; cobrança de pênalti com os mesmos dizeres conservadores dos deputados em votação pelo impedimento (golpe): "pela família, por Deus, pelo meu filho e meu neto" etc. ${ }^{41}$; uma possível saída de Cunha por quebra de decoro parlamentar ${ }^{42}$; troca de camisetas e cumprimentos afetuosos ao final da partida.

A partir desse interesse em mesclar política partidária, futebol e procedimentos artísticos, escrevemos um primeiro roteiro. Um time veste roxo e outro laranja. O jogo se inicia com Galvão Bueno dizendo: "Bem, amigos da Rede Globo, está começando agora a grande final de Brasil em Jogo, e essa final de campeonato promete. A partida de hoje tem o patrocínio das empresas Odebrecht, Angeloni, Petrobrás e Contas na Suíça do Deputado Eduardo Cunha. Vamos agora ao Hino Nacional obrigatório". A maior parte dos representantes políticos/jogadores está desatenta e não canta o hino da maneira correta, esquecendo algumas palavras ou cantando outra coisa, como é o caso de Tiririca, que canta "Florentina"43, sua música de sucesso, e de Feliciano, que canta "Pai Abraão"44, uma música evangélica. Como exceção à regra, Bolsonaro canta o hino do começo ao fim com o braço direito elevado e os dedos unidos, na forma do cumprimento do regime nazista de Adolf Hitler. Galvão apresenta cada um dos representantes políticos/jogadores, que, por sua vez, se cumprimentam e cumprimentam o juiz Moro, o qual se mostra mais receptivo ao time de Cunha. Temer está no banco de reserva e durante todo o jogo conversa com o público perguntando se são trabalhadores e pedindo a eles para não pensarem em crise, mas trabalharem ${ }^{45}$. Para as mulheres, Temer tece elogios, chamando-as de belas e perguntando se são recatadas e do $\operatorname{lar}^{46}$.

\footnotetext{
${ }^{40}$ Ocorrido durante a votação do impedimento (golpe) na Câmara dos Deputados em Brasília. Ver: <https://noticias.uol.com.br/politica/ultimas-noticias/2016/04/17/ jean-wyllys-cospe-em-bolsonaro-e-diz-que-faria-de-novo.htm>. Acesso em: 22 abr. 2017.

${ }^{41}$ Durante a votação do impedimento (golpe) na Câmara dos Deputados, muitos deputados aludiram a suas próprias famílias e a Deus, evidenciando que a razão do processo de impedimento não dizia respeito às pedaladas fiscais mas a uma questão moral, assim considerada por eles. Ver: <http://g1.globo.com/political processo-de-impeachment-de-dilma/noticia/2016/04/deus-filhos-veja-os-termos-mais-citados-na-votacao-do-impeachment.html>. Acesso em: 22 abr. 2017.

${ }^{42}$ Para mais informações, ver:

<http://www1.folha.uol.com.br/poder/2016/05/1768000-teori-afasta-eduardo-cunha-do-mandato-na-camara.shtml>. Acesso em: 22 abr.2017.

${ }^{43}$ A música pode ser conferida em: <https://www.letras.mus.br/tiririca/48950/>. Acesso em: 22/04/2017

${ }^{44}$ A música pode ser conferida em: <https://www.letras.com/cia-louvadeira/1166542/>. Acesso em: 22 abr. 2017.

${ }^{45}$ Essas falas de Temer se referem ao seu discurso de posse como presidente interino. Para mais informações, acesse:

<http://epocanegocios.globo.com/Brasil/noticia/2016/05/michel-temer-faz-seu-primeiro-discurso-e-ministros-tomam-posse.html>. Acesso em: 22 abr. /2017.

${ }^{46}$ Com referência à revista Veja, de abril de 2016, cuja capa mostra Marcela Temer, esposa de Michel Temer, com a frase "Bela, recatada e do lar". Consultar: <http://veja.abril.com.br/brasil/marcela-temer-bela-recatada-e-do-lar/>. Acesso em: 22 abr. 2017.
} 


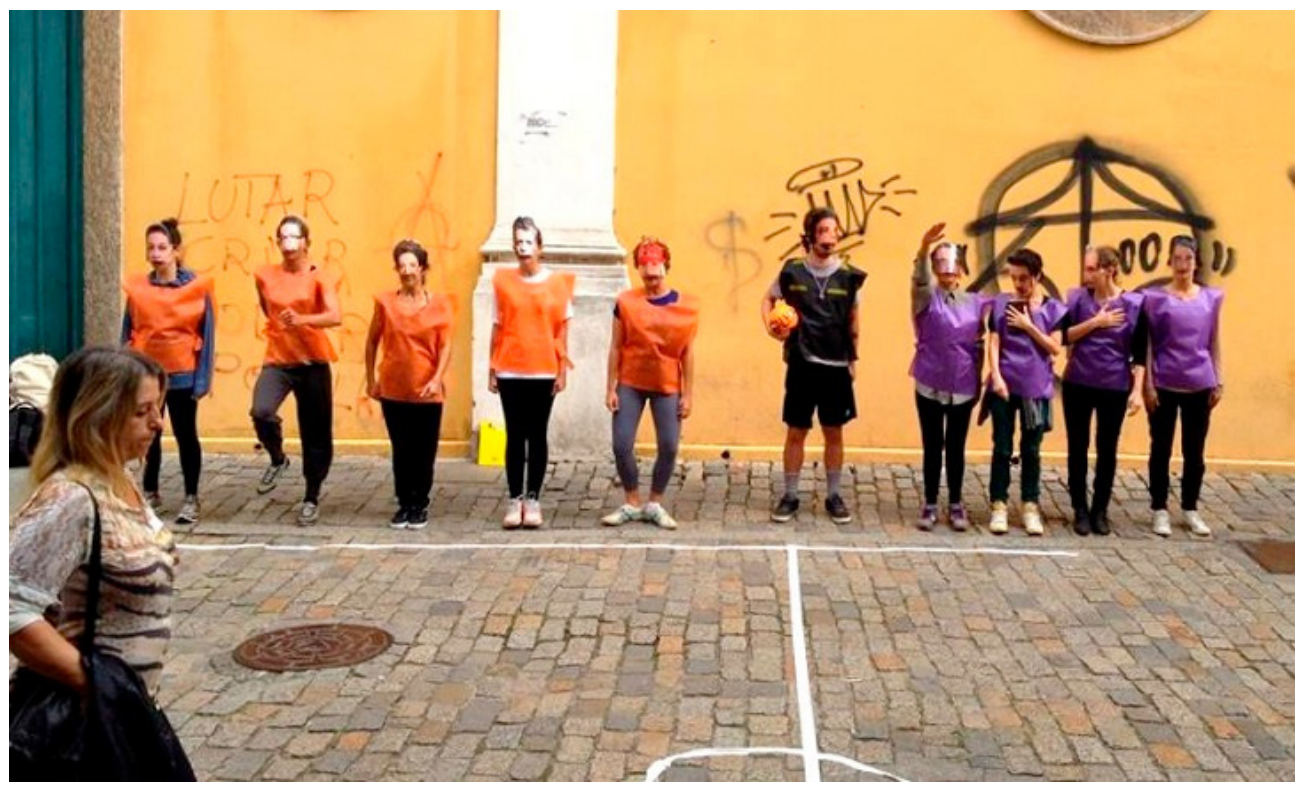

Registro de Brasil em Jogo, realizado no dia 03 de maio de 2016 no Largo da Alfândega, centro de Florianópolis, com: Raquel Purper, Diana Piazza, Diana Gilardenghi, Inês Saber, Paloma Bianchi, Giorgio Gislon, Cassiana dos Reis Lopes, Milene Duenha, Luana Leite e Thaina Gasparotto. Foto: Ciliane Bedin.

O roteiro base do jogo consistia na seguinte sequência de acontecimentos: juiz Moro coloca a bola (trabalhadora/trabalhador) no centro do campo. Primeiro gol feito por Lula, canta-se "olê-olê-olê-olá-Lula-Lula". Contra-ataque de Cunha, a defesa do time de Lula apenas observa sem se defender e acaba levando um gol. Lula sai de campo e passa a faixa ${ }^{47}$ de capitão para Dilma. Gol de Feliciano empurrando a bola (trabalhadora/trabalhador) com a Bíblia. Cunha chuta pra fora da trave e pede gol, juiz Moro valida o gol. Katia Abreu faz gol contra. Dilma, segurando uma folha de papel como uma espécie de liminar, pede ao juiz a volta de Lula ${ }^{48}$, mas juiz Moro não permite. Dilma se move como quem realiza uma pedalada de futebol ${ }^{49}$, Bolsonaro parte para cima dela e a derruba no chão, mas Dilma continua o movimento de pedalada deitada no chão. Moro dá cartão amarelo a Dilma. O time de Cunha grita: "Fora Querida", "Fora Dilma", "Fora PT"50. O time de Lula responde: "Pedalada não é crime". Tiririca pede para mudar de time e juiz Moro permite. Bolsonaro bate na bola (trabaIhadora/trabalhador), chuta a bola (trabalhadora/trabalhador), chuta e golpeia outros representantes políticos/jogadores. Jean Wyllys cospe em Bolsonaro e leva cartão amarelo de juiz Moro. É marcado um pênalti contra o time de Dilma, e Feliciano o cobra, dizendo: "Pela família, pela igreja, por Deus, pelo papagaio da minha vizinha, pelo meu cachorro voto SIM!"; Cunha esconde a bola (trabalhadora/trabalhador) e é expulso; Dilma, num ataque, sofre impedimento e recebe cartão vermelho de Moro ${ }^{51}$; Temer entra, dá um golpe em Dilma e rouba sua faixa presidencial; Temer paga ao Juiz Moro uma quantia de 39 mil reais $^{52}$. Fim do primeiro tempo. O segundo tempo

\footnotetext{
${ }^{47}$ A faixa de capitão representa a faixa presidencial e é feita de papel higiênico.

${ }^{48}$ Em referência à já citada tentativa de nomear Lula como ministro.

${ }^{49}$ Realizamos uma analogia entre a acusação de pedalada fiscal e a pedalada do futebol.

${ }^{50}$ Em referência aos comentários e aos cartazes empunhados pelos deputados e senadores durante as sessões de impedimento (golpe) na Câmara dos Deputados e no Senado Federal.

${ }^{51}$ Com os votos favoráveis de 367 deputados, 137 contrários e 7 abstenções, o Plenário da Câmara dos Deputados aprovou o relatório pró-impedimento.

${ }^{52}$ Em referência ao aumento dos salários do Judiciário aprovados pela Câmara, Senado e Presidência (golpista) da República (Michel Temer). Para mais infor-
} 
seria definido pela entrada de pessoas do público que, após nosso convite, tomariam a decisão sobre qual time defender.

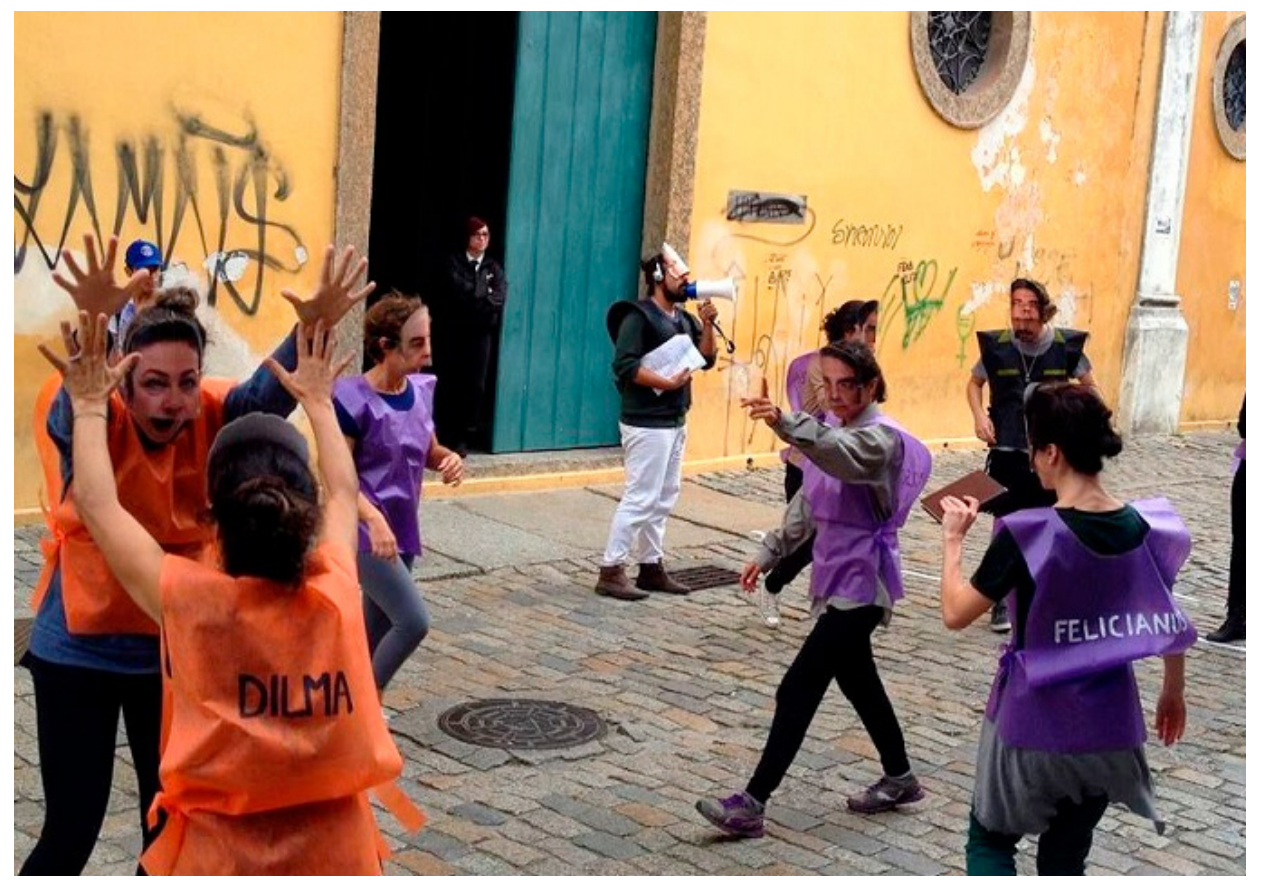

Registro de Brasil em Jogo, realizado no dia 03 de maio de 2016 no Largo da Alfândega, centro de Florianópolis, com: Diana Gilardenghi, Raquel Purper, Paloma Bianchi, Everton Lampe, Thaina Gasparotto, Cassiana dos Reis Lopes, Milene Duenha, Giorgio Gislon e Luana Leite. Foto: Ciliane Bedin.

Esse roteiro se manteve nas três ocasiões em que realizamos Brasil em Jogo; já os acontecimentos do jogo se mantiveram parcialmente, pois, ao tentarmos acompanhar os fatos da política, o modo de realização também se alterava. Retomando a ideia de arte contextual de Paul Ardenne (2006), a experiência vivenciada na ação se constitui em relação com a imediatez dos fatos e em relação com o contexto do espaço, exigindo de nós, artistas, que nos situássemos no espaço e no tempo locais. Assim, não era apenas o roteiro que determinava o que seria a ação Brasil em Jogo, mas também a presença de transeuntes. $O$ interesse do público em adentrar a partida interferiria radicalmente na estrutura pré-elaborada pelo grupo. Para Ardenne (2006), quando posta em relação, a arte se converte em prática ativa e reativa. Vivíamos os efeitos de se levar uma proposição artística aberta para a rua. As reações imediatas interferiam em nossas ações durante o jogo, e o convite a uma intervenção do público, por meio de sua entrada como jogador, definia os rumos da ação.

\section{Jogada espetacular - de olho no lance}

Saímos do espaço seguro da sala de ensaio para acompanhar a demanda interna do grupo e a externa, do cenário político. Tal investimento se deu a partir de nossa percepção das possibilidades de ação que a própria situação nos trazia, uma prática 
que tem sido cada vez mais discutida em processos compositivos nas artes da presença, afirmando uma "estrutura de acontecimento" 53.

A manutenção do trabalho como algo amplamente permeável pelos acontecimentos políticos e pelos acontecimentos no ato relacional traz como referência algumas características da performance. Porém, aspectos comumente atribuídos ao teatro também são explorados, como a ideia de representação. Nesse trabalho, existem dois movimentos de representação - representa-se o jogo de futebol e representa-se o jogo dos políticos brasileiros -, realizando uma sátira tanto desses personagens políticos, quanto do próprio esporte e suas regras. Com certo exagero paródico, as máscaras e as ações dos representantes políticos/jogadores apontam para uma comicidade ligada à postura dos políticos brasileiros e às situações vivenciadas naquele momento. Em uma sociedade em que tudo se mostra como espetáculo e se esvai na "fumaça da representação", como já discutiu Guy Debord (2003, p. 8), não é de se estranhar que ambos, política e futebol, sejam instituições cooptadas pelo mesmo processo de espetacularização. Da mesma maneira que a sociedade se apropriou da lógica do espetáculo (Debord, 2003), em Brasil em Jogo buscamos evidenciar as características espetaculares contidas na política por meio do futebol.

Destacamos, então, três espetáculos: o futebol, que, em certa medida, faz parte do cotidiano de muitos brasileiros, e que imbrica com uma intrincada trama de relações econômicas, sociais e políticas, que vão muito além do próprio esporte; o espetáculo da política, cujos interesses pessoais invariavelmente se sobrepõem aos do interesse coletivo, o que faz com que as coligações, as práticas e as desenvolturas políticas produzam situações contraditórias e embaraçosas; e, finalmente, o espetáculo de Brasil em Jogo, uma partida de futebol cujas regras são determinadas pelas situações da política brasileira.

Ao nos apropriarmos das formas de ação da política e do futebol, tentamos evidenciar as características futebolísticas e teatrais da política. O estar em jogo em supostos dois times brinca de maneira perversa com seus "torcedores", crentes de que estão sendo representados. Nessa ação, os jogadores nada mais são do que representações escrachadas dos políticos, ou seja, representações de representantes. Debord (1997, p. 13) escreve: "Toda a vida das sociedades nas quais reinam as modernas condições de produção se apresenta como uma imensa acumulação de espetáculos. Tudo o que era vivido diretamente tornou-se uma representação". Assim, os aspectos teatrais mais evidentes na ação Brasil em Jogo estão vinculados a essas noções de representação.

\section{A performance da torcida}

Após delimitarmos os papéis e as ações de cada pessoa do grupo, começamos a ensaiar as ações, mas, logo no primeiro momento, percebemos que o futebol ainda não estava encarnado em nossos corpos. Ele havia habitado nossas discussões, mas

${ }^{53}$ A exemplo do que coloca a pesquisadora cubana lleana Diéguez Caballero (2014, p. 128) ao descrever algumas características da arte contemporânea, observando uma teatralidade em campo expandido. Tal estrutura, estreitamente vinculada ao entorno, demanda uma expansão de fronteiras que vai desde o espaço físico a ser explorado nas proposições artísticas até seus procedimentos internos, seus modos de ser e produzir acontecimento.

Paloma Bianchi

Milene Lopes Duenha 
tecnicamente não éramos capazes de executá-lo. A nossa falta de técnica se juntou à dificuldade de enxergar através das máscaras. Éramos jogadores altamente questionáveis em campo, tanto em relação ao nosso próprio modo de jogar, quanto às figuras que representávamos. Isso se transformou também em um modo de provocar a participação do público.

Ensaiamos a sequência dos acontecimentos sabendo de antemão que o quando e o como cada ação aconteceria seriam determinados pelo entorno: o contexto político, o espaço em que a ação seria realizada e, principalmente, as pessoas que passavam, ou paravam para assistir, ou participavam de outras formas: por meio de comentários, torcendo para um dos times ou entrando para jogar.

A participação de transeuntes/público no aqui-agora da ação fazia emergir situações inesperadas, abrindo espaço para a imprevisibilidade e o risco. Esses elementos, comumente vinculados a aspectos da performance ${ }^{54}$, nos obrigavam a lidar com fatores inéditos, impedindo que tivéssemos total controle sobre o acontecimento. Entrar em campo se tornou uma emergência provocativa ao identificarmos a estrutura do futebol como vocabulário comum das ruas. Ao tencionar a impossibilidade de mudar o jogo pela posição de torcedora/torcedor, o público também era convidado a jogar. A entrada do público embaralhava os papéis de artista/espectador, assim como a estrutura dos próprios times, criando um espaço de acontecimentos incalculáveis. Tratar das investidas do público e das estratégias realizadas pelo grupo para a entrada de pessoas no jogo fez com que diversos conflitos éticos surgissem no contexto dessa ação a partir da realidade das ruas e da utilização de máscaras das figuras políticas que compunham os times reais, atuados e/ou performados.

\section{O índio não queria ser reserva}

Na primeira realização de Brasil em Jogo no Largo da Alfândega, centro de Florianópolis, no dia 3 de maio de $2016^{55}$, o impedimento (golpe) da presidente Dilma já havia sido votado na Câmara dos Deputados e estava tramitando no Senado Federal, sem ainda ter se efetivado. O público parava, observava e, inicialmente, fazia alguns comentários discretos. A percepção do que se tratava parecia clara. Alguns reagiam em concordância, outros nem tanto. Muitas vezes o foco era o próprio jogo de futebol e não as figuras que jogavam.

Havia abertura para participação do público. Assim ocorreu com três crianças que permaneceram na rua durante todo o tempo. Uma delas, que compôs o time de Lula - naquele momento em situação de desvantagem -, se mantinha incentivando o grupo a permanecer em jogo e não desistir. As outras demonstravam interesse pela bola (trabalhadora/trabalhador), com um detalhe: tratava-se de crianças indígenas guaranis que acompanhavam suas famílias na venda de artesanato no Largo da Alfân-

\footnotetext{
${ }^{54}$ Para a pesquisadora Roselee Goldberg (2006, p. 10): "A história da performance no século XX é a história de um meio de expressão maleável e indeterminado, com infinitas variáveis, praticado por artistas insatisfeitos com as limitações das formas mais estabelecidas e decididos a pôr a sua arte em contato direto com o público. Por esse motivo, tem sempre tido uma base anárquica. Devido a sua natureza, a performance dificulta uma definição fácil ou exata que transcenda a simples afirmação de que se trata de uma arte feita ao vivo pelos artistas".

${ }^{5}$ Neste link há uma edição da filmagem realizada do jogo:

<https://www.youtube.com/watch?v=TuW_sPZjQIY>. Acesso em: 22 abr. 2017.
} 
dega ${ }^{56}$. Todas as crianças queriam usar tanto as máscaras quanto os coletes. Assim, em jogo, estavam duas crianças indígenas vestindo as máscaras de Kátia Abreu e de Feliciano, e uma criança branca usando a máscara do Tiririca. Ficamos sem ação ao ver as crianças performando seus algozes, tendo em vista que Kátia Abreu representa a bancada ruralista, grupo da sociedade responsável pelo crescente extermínio das diversas etnias indígenas ${ }^{57}$, e Feliciano, evangélico extremista famoso por se colocar contra a multiplicidade de crenças religiosas e de pensamento. Cabia a nós e ao público a percepção política do que ali acontecia, sem ensaio prévio. Ao percebermos tais fatos, tentamos conversar com as crianças e pedimos que retirassem os coletes e as máscaras, mas elas não aceitaram a proposta. $O$ jogo seguiu desse modo até finalizarmos. Após o jogo, discutimos os problemas éticos de deixar as crianças representar tais personagens e acabamos por optar em não mais oferecer os coletes e máscaras ao público, deixando-o assumir o papel de "cidadãos" que agem no jogo.

\section{A polícia invade o campo}

Após a decisão do Senado pelo afastamento de Dilma do cargo de presidente, sentimos urgência para dar continuidade às partidas do Brasil em Jogo. Voltamos ao Largo da Alfândega no dia 20 de maio de 2016, dessa vez como forma de apoiar o Ocupa Minc $\mathrm{SC}^{58}$, que passava por um momento tenso em relação à polícia militar. Colocamos nossos uniformes e fomos à rua. Nesse dia, o jogador Michel Temer estava no banco de reservas do time de Lula. Havíamos ensaiado um pouco mais na tentativa de estabelecer um roteiro mais definido de ações que pudéssemos executar com mais precisão. Essa escolha modificou o jogo pois, ao voltarmos a atenção para a execução de cenas utilizando recursos de ensaio - como ralentar as ações, ordenar sequencialmente as falas, em vez de jogarmos no tempo e em condições precárias -, transformou-se também a relação com o público. O público, que antes se incomodava com o fato de jogarmos mal, de chutarmos a bola para fora sem querer, agora assistia ao que era apresentado. Uma pessoa chegou a perguntar por que não jogávamos "de verdade".

Assumir uma perspectiva mais marcada fazia com que o trabalho se configurasse como algo a ser observado e, possivelmente, com menor interferência em sua estrutura interna. Pelo fato de estarmos realizando a ação durante a ocupação, a participação aconteceu de outro modo, majoritariamente por parte dos ocupantes que incentivavam o time laranja. Alguns questionaram a presença de Kátia Abreu no time laranja, ignorando o fato de que ela foi ministra de Dilma até seu afastamento pelo Senado. Também questionaram a presença de Temer no time de Lula, de novo igno-

\footnotetext{
${ }^{56}$ Espaço localizado no centro de Florianópolis, cujo movimento de pessoas é intenso e onde há vários comerciantes ambulantes, incluindo os indígenas guaranis. De acordo com o texto de Franciele Krusczynski e Luiza john Reis (2016), grande parte dessas famílias pertencem a tribo Guarani localizada no Morro dos Cavalos, no Município de Palhoça (a 15 quilômetros de Florianópolis). Elas fazem o trajeto entre cidades todos os dias para venderem seus artesanatos.

${ }^{57}$ Para mais informações, acesse:

<http://brasil.elpais.com/brasil/2016/06/20/opinion/1466431465_758346.html>. Acesso em: 22 abr. 2017.

${ }^{58}$ Artistas e estudantes de arte ocuparam o prédio do IPHAN em protesto e em resistência à extinção do Ministério da Cultura pelo presidente interino Michel Temer. O prédio do IPHAN-MINC de Florianópolis foi ocupado no dia 19 de abril de 2016, devido à sua retirada do Ministério da Cultura e transformação em secretaria do Ministério da Educação, logo no início do governo Temer.
}

Paloma Bianchi

Milene Lopes Duenha 
rando o fato de que Temer era o vice de Dilma desde o primeiro mandato. Grande parte deles também gritavam por Lula e por Dilma e insultavam o time de Cunha. Os comentários do público funcionavam como uma espécie de feedback instantâneo da ação, mas também remetiam aos comentários que os próprios torcedores fazem durante uma partida de futebol.

Um carro de polícia entrou na nossa "quadra" na tentativa de intervir no que acontecia, e Jair Bolsonaro deixou de jogar para estender a mão aos policiais. Um estado de tensão foi gerado entre os ocupantes e a polícia, diante de diversas ameaças de desocupação por violência policial. Nossa ação foi interrompida antes da realização do segundo tempo, momento em que a participação dos transeuntes/público aconteceria de modo mais incisivo, por não haver uma estrutura rígida pautada no roteiro. Os ocupantes pediram para que interrompêssemos a ação e entrássemos no prédio por questões de segurança.

\section{Foi gol sim}

A terceira realização de Brasil em Jogo se deu no dia 21 de maio de 2016, no Sarau Lunático do Engenho do Zé59. Como não havia artistas suficientes para ocupar os postos de todos os políticos elencados inicialmente, optamos por manter Lula, Dilma, Jean Wyllys, Katia Abreu, Tiririca e Michel Temer (na reserva) no time de Lula, enquanto o time de Cunha seria representado por ele, Bolsonaro e Feliciano. Começar com vantagem para o time de Lula nos pareceu coerente, já que isso corresponde aos 8 anos do governo do ex-presidente, durante o qual não havia uma oposição tão forte e presente, pois o PMDB fazia parte da coligação do PT. Conforme o jogo se desenvolvia, a vantagem se transpôs ao time de Cunha, como de fato aconteceu, vide os últimos dois anos de mandato de Dilma.

Nessa ocasião, no segundo tempo do jogo, alguns de nós decidiram tirar as máscaras e vestir coletes sem nomes. Distribuímos coletes - também sem nome - às crianças que quiseram jogar (nenhum adulto se prontificou a entrar no jogo). Assim, formamos dois times: de um lado estavam Cunha, Temer e Bolsonaro; de outro estavam as crianças. Nossa vontade inicial de oferecer agência ao público se mostrou ineficaz em certa medida, pois as crianças só estavam interessadas no jogo de futebol e não compreendiam o jogo político que estávamos apresentando. Os adultos não participaram do jogo, mantendo-se como espectadores do jogo político. Um fato, porém, nos chamou a atenção durante o jogo: do mesmo modo que acontece na partida de futebol, a torcida afirmava que alguns lances eram prejudiciais a seu time, mesmo que isso não fosse verdade. Pedia-se pênalti quando não havia, pedia-se falta quando não havia. Isso também ocorreu quando as crianças entraram. Especialmente na fala de um pai, que afirmava que seu filho havia marcado gol quando a bola de fato havia ido para fora do campo, reproduzindo-se as mesmas estratégias de corrupção evidentes, sejam as apresentadas na primeira parte do jogo, sejam as presentes no cotidiano.

${ }^{59}$ Centro Cultural do bairro Santinho, em Florianópolis-SC 


\section{O jogo só acaba quando termina; ou 0 jogo só acaba quando o juiz apita; ou $O$ jogo extrapola os 45 do segundo tempo}

Nossos finais foram sempre uma problemática aberta: as crianças indígenas que vestem os coletes de políticos que os prejudicaram historicamente, a interrupção pela presença da polícia, as crianças que entram e cujos pais participam apenas de longe, fazendo comentários e expondo a trivialidade da corrupção no cotidiano. A continuidade dessa ação demandaria uma constante abertura a sua remontagem a partir de outras regras, novas situações de jogo, em um processo extensivo de acordo com as mudanças contextuais.

As complexidades e divergências encontradas no assunto político foram motores para a produção de Brasil em Jogo, que se baseava em um conjunto de questões vividas por todos os cidadãos brasileiros, de diferentes formas. A consequência desse investimento foi a formulação de algo muito distinto de uma "obra de arte" a ser contemplada. Ao contrário, a opção por acessar um conteúdo cujas mudanças se davam freneticamente não nos permitia controlar os rumos do trabalho.

Em Brasil em Jogo buscamos evidenciar, de maneira bem humorada e irônica, as jogadas políticas, e oferecer a visão dessas mesmas jogadas como um modo de subversão de suas táticas. Entretanto, a estratégia de jogo futebolístico operada pelo Coletivo Mapas e Hipertextos corre também o risco de ser cooptada por uma lógica social do espetáculo (Debord; 1997), o que a transformaria em um modelo de entretenimento anestesiante. Esses diversos temas políticos caberiam perfeitamente na realidade do entretenimento e do futebol, revelando o absurdo com que os temas políticos são acolhidos pela opinião pública, que se posiciona ora por gritos e manifestações, ora "abrindo uma cerveja", não percebendo ou mesmo desconsiderando sua responsabilidade em relação às decisões necessárias.

Longe de ter um final, assim como em Brasil em Jogo, essa longa história prossegue, para ser reformulada, recontada, revivida. No presente momento, uma percepção possível é a de que a bola da vez é a bola (trabalhadora/trabalhador). O Brasil continua em jogo.

\section{Referências}

ARDENNE, Paul. Un arte contextual: Creación artística en medio urbano, en situación, de intervención, de participación. Murcia: CENDEAC, 2006.

CABALLERO, lleana, D. Um teatro sem teatro: a teatralidade como campo expandido. Trad. Eli Borges, Revista Sala Preta, vol. 14, p. 125-129. São Paulo, 2014.

DAMO, Arlei Sander. Futebol e estética. São Paulo Perspec., São Paulo , v. 15, n. 3, p. 82-91, 2001. Disponível em: <http://www.scielo.br/scielo.php?script=sci_arttext\&pid=S 0102-88392001000300011\&lng=en\&nrm=iso>. Acesso em: 7 jul. 2016. 
DEBORD, Guy. A sociedade do espetáculo. Rio de Janeiro: Contraponto, 1997.

GOLDBERG, Roselee. A arte da performance - Do futurismo ao presente. São Paulo: Martins Fontes, 2006.

KRUSCZYNSKI, Franciele; REIS, Luiza John. O artesanato como meio de subsistência. 2016. Disponivel em: <https://medium.com/@mulheresindigenasdailha/mulheres-ind\%C3\%ADgenas-a-arte-como-forma-de-subsist\%C3\%AAncia-669382067496>. Acesso em: 22 jun. 2017.

LEE-MEDDI, Jeocaz. Copa de 1970 e a ditadura militar. VIRTUÁLIA - O Manifesto Digital. 2010. Disponível em: <http://virtualiaomanifesto.blogspot.com.br/2010/01/ copa-de-1970-e-ditadura-militar.html>. Acesso em: 9 jul. 2016.

VILARINHO, Carlos Ferreira. Quem derrubou João Saldanha. Rio de Janeiro: Livros de Futebol, 2010.

Recebido em: 27/04/2017 Aprovado em: 22/06/2017 